Pacific Journal of Mathematic 


\title{
A NONIMBEDDING THEOREM OF NILPOTENT LIE ALGEBRAS
}

\section{ChONG-Yun ChaO}

\begin{abstract}
There are many similarities between groups of prime power order and nilpotent Lie algebras. Here we present a nonimbedding theorem in nilpotent Lie algebras which is an analogue of a nonimbedding theorem of Burnside in groups of prime power order.
\end{abstract}

Burnside in [2] proved the following two theorems:

THEOREM B1. A nonabelian group whose center is cyclic cannot be the derived group of a p-group.

TheOREM B2. A nonabelian group, the index of whose derived group is $p^{2}$, cannot be the derived group of a p-group.

Hobby in [3] proved the following analogues of the theorems of Burnside :

THEOREM H1. If $H$ is nonabelian group whose center is cyclic, then $H$ cannot be the Frattini subgroup of any p-group.

THEOREM H2. A nonabelian group, the index of whose derived group is $p^{2}$, cannot be the Frattini subgroup of any p-group.

The purpose of this note is to establish the analogues of the theorems of Burnside in Lie algebras. The main result is the following Theorem 1. The Lie algebras which we consider here are finite dimensional over an arbitrary field $F$. The Frattini subalgebra $\phi(M)$ of a Lie algebra $M$ is defined as the intersection of all maximal subalgebras of $M$. We also show that in a nilpotent Lie algebra $N, \phi(N)$ coincides with the derived algebra of $N$. Hence, the analogues of Hobby's theorems in Lie algebras are the same as the analogues of Burnside's theorems in Lie algebras.

THEOREm 1. A nonabelian Lie algebra $L$ whose center is one dimensional cannot be any $N_{i}, i \geqq 1$, of a nilpotent Lie algebra $N$ where $N=N_{0} \supset N_{1} \supset N_{2} \supset \cdots \supset N_{t} \supset 0$ is the lower central series of $N$.

Proof. Suppose the contrary, i.e., $L=N_{i}$ for some $i, 1 \leqq i<t$, 
in $N$. Since $L$ is nonabelian, $L \neq N_{t}$. Let $z$ be a basis of the center of $L$, denoted by $Z(L)$. The following Jacobi identity

$$
[[u, z], x]+[[z, x], u]+[[x, u], z]=0
$$

holds for every $u \in N$ and every $x \in L$. Since $z \in Z(L)$, the second term of the identity zero. The third term of the identity is also zero since $L$ is $N_{i}$ and $N_{i}$ is an ideal in $N$. Hence, we have $[[u, z], x]=0$ for every $x \in L$ and every $u \in N$, i.e., $[u, z] \in Z(L)$ and $[u, z]=a_{u} z$ where $a_{u} \in F$.

There are two cases : (1) If $a_{u} \neq 0$ for some $u \in N$, then the lower central series of $N$ never reaches zero, that is a contradiction to $N$ being nilpotent. (2) The case $[u, z]=0$ for every $u \in N$. Then $z \in Z(N)$, i.e., $Z(L) \subseteq Z(N)$. Since $N / Z(L)$ is nilpotent, we have $(N / Z(L)) \supset\left(N_{1} / Z(L)\right) \supset \cdots \supset\left(N_{i} / Z(L)\right)=(L / Z(L)) \supset \cdots \supset\left(N_{t} / Z(L)\right) \supseteqq 0$ where we have $N_{t}=Z(L)$ since $N_{t} \cong Z(N)$ and $L=N_{i}$ and the dimension of $Z(L)$ is one. There is a nonzero $\bar{y} \in Z(N / Z(L)) \cap(L / Z(L))$, i.e., $\bar{y} \in\left(N_{t-1} / Z(L)\right)$. Then $[\bar{y}, \bar{v}]=\overline{0}$ for every $\bar{v} \in N / Z(L)$, i.e., $[y, v]=a_{v y} z$ where $a_{v y} \in F, \bar{y}=y+Z(L)$ and $\bar{v}=v+Z(L)$. Let $w$ be any element in $N$, by using Jacobi identity, we have

$$
[y,[v, w]]=\left[a_{v y} z, w\right]+\left[v, a_{w y} z\right]=0,
$$

i.e., $y$ commutes with every element in $N_{1}$. In particular, $y$ commutes with every element in $L$. That contradicts the dimension of $Z(L)$ being one. Hence, the proof is completed.

THEOREM 2. A nonabelian Lie algebra $L$, the dimension of $\left(L / L_{1}\right)$ is 2, cannot be any $N_{i}, i \geqq 1$, of a nilpotent Lie algebra $N$ where $N=N_{0} \supset N_{1} \supset N_{2} \supset \cdots \supset N_{t} \supset 0$ is the lower contral series of $N$.

Proof. Suppose the contrary, i.e., $L$ is some $N_{i}, t<i \leqq 1$. Then $L$ is nilpotent. We claim that the dimension of $L / L_{1}$, denoted by $\operatorname{dim}\left(L / L_{1}\right)$, is 2 implying that $\operatorname{dim}\left(L_{1} / L_{2}\right)=1$. Suppose $\operatorname{dim}\left(L_{1} / L_{2}\right)>1$, then there exist linearly independent vectors $\bar{x}$ and $\bar{y}$ in $\bar{L}_{1}=L_{1} / L_{2}$, and there also exist linearly independent vectors $\bar{u}$ and $\bar{v}$ in a complement $\bar{C}$ of $\bar{L}_{1}$ in $\bar{L}$ such that $[\bar{u}, \bar{v}]=\bar{x}$. Similarly, there exist $\bar{u}^{\prime}, \bar{v}^{\prime} \in \bar{C}$ such that $\left[\bar{u}^{\prime}, \bar{v}^{\prime}\right]=\bar{y}$. Since $\operatorname{dim} \bar{C}=2,\left[\bar{u}^{\prime}, \bar{v}^{\prime}\right]=a[\bar{u}, \bar{v}]$ where $a \in F$. This contradicts the linear independence of $\bar{x}$ and $\bar{y}$. Hence, $\operatorname{dim}\left(L_{1} / L_{2}\right)=1$.

Since $L_{2}$ is a characteristic ideal of $L, L_{2}$ is an ideal in $N$. Then, the Lie algebra $N / L_{2}$ contains $L / L_{2}$ as a term in its lower central series. Since the center of $L / L_{2}$ is one dimensional and $L / L_{2}$ is nonabelian, this is impossible by Theorem 1 . 
THEOREM 3. If $N$ is a nilpotent Lie algebra, then $\phi(N)=N_{1}$.

Proof. If $N$ is abelian then $\phi(N)=N_{1}=0$. Consider that $N$ is nilpotent and nonablelian: Let $u_{1}, u_{2}, \cdots, u_{k}$ be a basis a complementary subspace $U$ of $N_{1}$ in $N$, it is easy to verify that $k$ must be $\geqq 2$, and let $U_{i}=\left(\left(u_{1}\right)\right)+\cdots+\left(\left(u_{i-1}\right)\right)+\left(\left(u_{i+1}\right)\right)+\cdots+\left(\left(u_{k}\right)\right)+N_{1}, i=$ $1,2, \cdots, k$, where the sums are direct sums of vector spaces. Clearly, each $U_{i}$ is a maximal subalgebra of $N$. Then $\phi(N) \leqq \bigcap_{i=1}^{k} U_{i}=N_{1}$.

Now, we show that $\phi(N) \supseteqq N_{1}$. Let $M_{\alpha}$ be a maximal subalgebra of $N$. It follows from Proposition 3 on p. 56 in [1] that every maximal subalgebra in a nilpotent Lie algebra is an ideal. Hence, $M_{\alpha}$ is an indeal in $N$. Let $x$ be a nonzero vector in $N$ and $x \notin M_{\alpha}$, then the direct sum of the vector spaces $((x))$ and $M_{\alpha}$ constitutes a subalgebra. Since $M_{\alpha}$ is maximal, $((x))+M_{\alpha}=N$. Since $M_{\alpha}$ is an ideal of $N$ and since $N / M_{\alpha}$ is of dimension one and since $N / M_{\alpha}$ is nilpotent, we have

$$
N / M_{\alpha} \supset N_{1} M_{\alpha}=\overline{0},
$$

i.e., $M_{\alpha} \supseteq N_{1}$ for any maximal subalgebra $M_{\alpha}$. Consequently, $\phi(N)=$ $\bigcap_{\alpha} N_{\alpha} \supseteqq N_{1}$, and $\phi(N)=N_{1}$.

COROLlary 1. If $L$ is a nonabelian Lie algebra whose center is one dimensional, then $L$ cannot be the Frattini subalgebra of any nilpotent Lie algebra.

It follows from Theorem 3 and Theorem 1.

Corollary 2. A nonabelian Lie algebra $L$, $\operatorname{dim}\left(L / L_{1}\right)=2$, cannot be the Frattini subalgebra of any nilpotent Lie algebra.

It follows from Theorem 3 and Theorem 2.

Our Theorem 1 and Theorem 2 contain the analogues of Theorem B1 and Theorem B2 respectively. Corollary 1 and Corollary 2 of Theorem 3 are the analogues of Theorem $\mathrm{H} 1$ and Theorem $\mathrm{H} 2$ respectively.

REMARK. The following example shows that for each integer $n \geqq 3$ there is a nonabelian nilpotent Lie algebra $L$ of dimension $n$ whose center is one dimensional (also, the dimension of $L / L_{1}$ is 2): Let $L=\left(\left(x_{1}, x_{2}, \cdots, x_{n}\right)\right)$ with a bilinear anti-symmetric bracket multiplication such that $\left[x_{1}, x_{i}\right]=x_{i+1}$ for $i=2,3, \cdots, n-1$, and all other products are zero. 


\section{REFERENCES}

1. N. Bourbaki, Éléments de Mathématique XXVI, Groups et Algèbres de Lie, Chap. 1, Paris, 1960.

2. W. Burnside, On some properties of groups whose orders are powers of primes, Proc. Lond. Math. Soc. (2) 11 (1912), 225-245.

3. C. Hobby, The Frattini subgroup of a p-group, Pac. J. Math. 10 (1960), 209-212.

Received July 19, 1966, and in revised from August 1, 1966.

UNIVERSITY OF PITTSBURGH 


\section{PACIFIC JOURNAL OF MATHEMATICS}

\section{EDITORS}

\section{H. SAMELSON}

Stanford University

Stanford, California

J. P. JANS

University of Washington

Seattle, Washington 98105

\section{J. DugundJI}

University of Southern California Los Angeles, California 90007

RICHARD ARENS

University of California

Los Angeles, California 90024

\section{ASSOCIATE EDITORS}

E. F. BECKENBACH
B. H. NeUmanN

\section{SUPPORTING INSTITUTIONS}

UNIVERSITY OF BRITISH COLUMBIA CALIFORNIA INSTITUTE OF TECHNOLOGY

UNIVERSITY OF CALIFORNIA

MONTANA STATE UNIVERSITY

UNIVERSITY OF NEVADA

NEW MEXICO STATE UNIVERSITY

OREGON STATE UNIVERSITY

UNIVERSITY OF OREGON

OSAKA UNIVERSITY

UNIVERSITY OF SOUTHERN CALIFORNIA

\author{
STANFORD UNIVERSITY \\ UNIVERSITY OF TOKYO \\ UNIVERSITY OF UTAH \\ WASHINGTON STATE UNIVERSITY \\ UNIVERSITY OF WASHINGTON \\ AMERICAN MATHEMATICAL SOCIETY \\ CHEVRON RESEARCH CORPORATION \\ TRW SYSTEMS \\ NAVAL ORDNANCE TEST STATION
}

Mathematical papers intended for publication in the Pacific Journal of Mathematics should be typewritten (double spaced). The first paragraph or two must be capable of being used separately as a synopsis of the entire paper. It should not contain references to the bibliography. Manuscripts may be sent to any one of the four editors. All other communications to the editors should be addressed to the managing editor, Richard Arens at the University of California, Los Angeles, California 90024.

50 reprints per author of each article are furnished free of charge; additional copies may be obtained at cost in multiples of 50 .

The Pacific Journal of Mathematics is published monthly. Effective with Volume 16 the price per volume ( 3 numbers) is $\$ 8.00$; single issues, $\$ 3.00$. Special price for current issues to individual faculty members of supporting institutions and to individual members of the American Mathematical Society: $\$ 4.00$ per volume; single issues $\$ 1.50$. Back numbers are available.

Subscriptions, orders for back numbers, and changes of address should be sent to Pacific Journal of Mathematics, 103 Highland Boulevard, Berkeley 8, California.

Printed at Kokusai Bunken Insatsusha (International Academic Printing Co., Ltd.), 7-17, Fujimi 2-chome, Chiyoda-ku, Tokyo, Japan.

\section{PUBLISHED BY PACIFIC JOURNAL OF MATHEMATICS, A NON-PROFIT CORPORATION}

The Supporting Institutions listed above contribute to the cost of publication of this Journal, but they are not owners or publishers and have no responsibility for its content or policies. 


\section{Pacific Journal of Mathematics}

\section{Vol. 22, No. $2 \quad$ February, 1967}

Paul Frank Baum, Local isomorphism of compact connected Lie groups ....

Lowell Wayne Beineke, Frank Harary and Michael David Plummer, On the

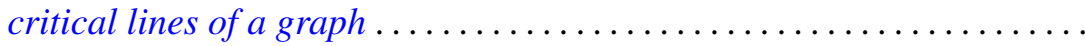

Larry Eugene Bobisud, On the behavior of the solution of the telegraphist's equation for large velocities .......................... 213

Richard Thomas Bumby, Irreducible integers in Galois extensions . . . . . . 221

Chong-Yun Chao, A nonimbedding theorem of nilpotent Lie algebras ..... 231

Peter Crawley, Abelian p-groups determined by their Ulm sequences ...... 235

Bernard Russel Gelbaum, Tensor products of group algebras ........... 241

Newton Seymour Hawley, Weierstrass points of plane domains .......... 251

Paul Daniel Hill, On quasi-isomorphic invariants of primary groups . . . . . 257

Melvyn Klein, Estimates for the transfinite diameter with applications to confomral mapping ................................ 267

Frederick M. Lister, Simplifying intersections of disks in Bing's side approximation theorem ............................. 281

Charles Wisson McArthur, On a theorem of Orlicz and Pettis ........... 297

Harry Wright McLaughlin and Frederic Thomas Metcalf, An inequality for

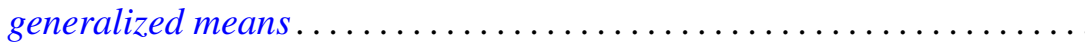

Daniel Russell McMillan, Jr., Some topological properties of piercing

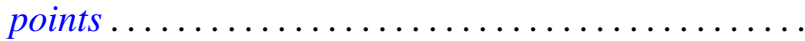

Peter Don Morris and Daniel Eliot Wulbert, Functional representation of topological algebras .

Roger Wolcott Richardson, Jr., On the rigidity of semi-direct products of Lie algebras..................................

Jack Segal and Edward Sandusky Thomas, Jr., Isomorphic

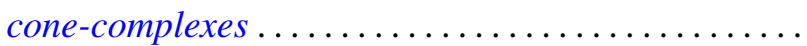

Richard R. Tucker, The $\delta^{2}$-process and related topics.... 